\title{
The need to grow our own: research is a priority for diabetes nursing
}
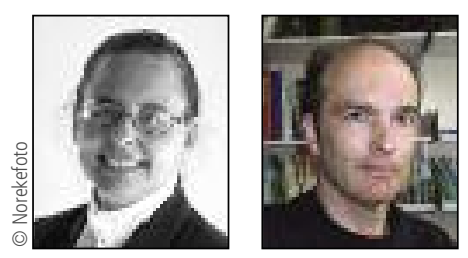

Florence Nightingale said 'I think one's feelings waste themselves in words; they ought all to be distilled into actions which bring results.' Actions that bring results, that benefit patients, should be at the core of the diabetes nursing community.

However, all actions need to be measured and targeted to the needs of the patient, such that they will do no harm and will enhance the patient's wellbeing. Ensuring that we provide the right care or intervention at the right time requires knowledge. Knowledge that is transparent and based on enduring principles or theories. Such knowledge is found through research, research into what patients need and how best to meet those needs. Research is not an isolated endeavour nor is it a luxury: it should in every sense define the meaning of what the diabetes nurse thinks and does. If diabetes nursing is to flourish as a specialism, then we need a vibrant and active research community.

\section{An encouraging growth...}

In this edition of European Diabetes Nursing we have an important piece of work by Graue and colleagues. Their paper presents a review of published research undertaken in the Nordic countries (Denmark, Iceland, Norway and Sweden) from 1979 to 2009. The results are quite encouraging in that they show a marked increase in the number of peer-reviewed submissions over three decades. This increase is particularly marked since 2000 and it shows that Sweden is leading the way in terms of output.

However, while this is a very encouraging trend, there is little room for complacency here. The majority of these studies are descriptive or are related to the development of measures; there are very few studies that are orientated to developing interventions that tackle specific patient needs.

These findings are similar to a previous review of nursing research, which highlighted the need to develop more clinically orientated research with strong theoretical underpinning and focused on important patient-centred problems. ${ }^{1}$ While diabetes research is rightly a multidisciplinary endeavour, there are many areas where nurses can and should be taking the lead. These areas include: psychological distress and adjustment; self-management support; and dealing with diabetes complications and symptoms - to name a few. Indeed, in this edition of the journal we have important topics such as wound care in older people and patient centredness.

\section{...further cultivation is urgently needed}

There are, of course, many challenges in developing programmers of integrated research. These include funding opportunities and, more fundamentally, the need to have a research-prepared workforce. Hence, the green shoots that are evident in the Nordic region of Europe need to be carefully cultivated and seeded elsewhere. We need a variety of species in the range of research flora that we produce from scented flowers (novel ideas) to sturdy trees (clinical trials). In order for this to happen we need fertile soil and strong roots.

To this end, we need to develop strong pre- and postdoctoral training programmes. We also need to share our work and to foster greater international collaboration and propose integrated research programmes of scale to funders.

FEND has begun this process by investing in research training posts and through their vision for developing a centre for clinical practice and research for European diabetes nurses. However, such a centre can only flourish through a strong network or community of diabetes nurse researchers. So now is the time to act on this.

Please get in touch with us with your thoughts or opinions on developing research in diabetes nursing. There are many innovative diabetes nurses delivering novel practices; these practices need to be researched, so that those that are beneficial are adopted more widely providing the foundation for good quality diabetes care.

\section{Magdalena Annersten Gershater \\ Angus Forbes \\ Co-editors, \\ European Diabetes Nursing}

\section{Reference}

1. Forbes A. Clinical intervention research in nursing; a discussion paper. Int J Nurs Stud 2009;46:557-68. 